\title{
Neonatal Tetanus at Pediatric Teaching Hospital in Bangui
}

\author{
Jean Chrysostome Gody1,2, Marie Christine Awa Sepou Yanza',2, \\ Olivier Brice Bogning Mejiozem1, Victoire NGatimo1, Franck Houndjahoué1, \\ Vanessa Iris Gaspiet Sonny ${ }^{1}$, Evodie Pierrette Kakounguere ${ }^{1}$, Baptistine Anguize1, \\ Aymard Trésor Guénefio ${ }^{1}$, Aristide Prince Mbeko', Moyen Engoba ${ }^{3}$, Georges Moyen ${ }^{3}$ \\ ${ }^{1}$ Centre Hospitalier Universitaire Pédiatrique de Bangui, Bangui, Central African Republic \\ ${ }^{2}$ Faculté des Sciences de la Santé de l'Université de Bangui, Bangui, Central African Republic \\ ${ }^{3}$ Université Marien Ngouabi, Brazzaville, Republic of Congo \\ Email: jcgody@hotmail.com
}

How to cite this paper: Gody, J.C., Yanza, M.C.A.S., Mejiozem, O.B.B., NGatimo, V., Houndjahoué, F., Sonny, V.I.G., Kakounguere, E.P., Anguize, B., Guénefio, A.T., Mbeko, A.P., Engoba, M. and Moyen, G. (2021) Neonatal Tetanus at Pediatric Teaching Hospital in Bangui. Open Journal of Pediatrics, 11, 179-188.

https://doi.org/10.4236/ojped.2021.112017

Received: March 4, 2021

Accepted: May 23, 2021

Published: May 26, 2021

Copyright $\odot 2021$ by author(s) and Scientific Research Publishing Inc. This work is licensed under the Creative Commons Attribution International License (CC BY 4.0).

http://creativecommons.org/licenses/by/4.0/ (c) (i) Open Access

\begin{abstract}
Background: Despite the Maternal and Neonatal Tetanus (MNT) elimination initiative, neonatal tetanus still persists in some parts of the world. Objectives: To determine hospital prevalence and describe epidemiological, clinical, therapeutic and outcome aspects of neonatal tetanus at the Pediatric Teaching Hospital in Bangui. Methodology: It was the review of hospitalized newborns' files in the neonatal unit at Pediatric Teaching Hospital in Bangui between January 2016 and December 2019. Newborns discharged with tetanus diagnosis, and whose files were usable were included. The variables studied were: for the newborn: age, sex, birth weight, the reason for transfer, diagnosis, cause and time of death, place and method of delivery; for the mother: age, antenatal care, tetanus vaccine status, parity and geographical provenance. Epi Info 7 software, version 7.1.3.3 was used for data analysis. The chi2 test with the significance level set at $\mathrm{p}<0.05$ and the odds ratio were used. Résultats: Forty-eight (48) out of 5796 newborns had neonatal tetanus (0.8\%). They were newborns to mothers with an average age of 18.8 years of which $68.8 \%(n=33)$ were primipara and $87.5 \%(n=42)$ not vaccinated against tetanus. Childbirth happened at home in $91.7 \%(\mathrm{n}=44)$, and the blade was used for sectioning the umbilical cord in $39.6 \%(\mathrm{n}=19)$. Newborns were referred from rural area in $47.9 \%(n=23)$. A single antenatal care contact was done in $68.7 \%(\mathrm{n}=33)$. Tetanus was classified as severe according to the Dakar prognosis score between 4 and 6 in $89.6 \%$ of cases $(n=43)$. The death occurred in $58.3 \%(n=28)$. Conclusion: The high frequency of neonatal tetanus as well as its severity requires pregnancy follow-up strengthening and childbirth monitoring in order to its elimination. But primary prevention re-
\end{abstract}


lies on improving individual and general hygiene conditions.

\section{Keywords}

Neonatal Tetanus, Childbirth, Mortality, Bangui

\section{Introduction}

Neonatal tetanus (NT), a serious vaccine-preventable toxic infection, is a public health issue [1]. It is responsible for mortality approaching 100\%; exceeding $50 \%$ even with appropriate hospital care [2]. Its elimination, a world goal, is closely associated with maternal tetanus [3]. Thus, maternal immunization made it possible to protect $82 \%$ of newborns against tetanus and the reduction of mortality by 93\% between 1980 and 2010; highlighting, therefore, the positive impact of the elimination initiative of maternal and neonatal tetanus by WHO [4] [5]. Since 2015 , neonatal tetanus remains a major public health problem (with an incidence rate of at least one case per 1000 live births at the district level) in 23 countries: Afghanistan, Angola, Cambodia, Central African Republic, Chad, Democratic Republic of Congo, Equatorial Guinea, Ethiopia, Haiti, India, Indonesia, Iraq, Kenya, Mali, Niger, Nigeria, Pakistan, Papua New Guinea, Philippines, Somalia, Sudan, South Sudan and Yemen [6]. In December 2018, the elimination initiative was reached in 45 out of 59 countries. The remaining countries being mostly in African regions and Eastern Mediterranean, where conflicts are delaying the global maternal and neonatal tetanus elimination goal till 2020 [3] [7]. The purpose of this study is to contribute to the elimination of neonatal tetanus and the objectives are to determine the hospital prevalence, and describe the epidemiological, clinical and therapeutic aspects as well as the outcome of hospitalized newborns for neonatal tetanus in the neonatal unit at the Pediatric Teaching Hospital in Bangui.

\section{Patients and Methods}

It was the review of the files of hospitalized newborns in the neonatology unit at the Pediatric Teaching Hospital, the single national hospital for newborns care in the CAR. Newborns hospitalized between January 2016 and December 2019-i.e. in four years-and whose files were usable, were included. We excluded newborns dead upon arrival. The variables studied were: for the newborn: age, sex, birth weight, diagnosis, cause and time of death, place and method of delivery; for the mother: age, antenatal care, immunization status, parity and geographical provenance. The data were collected from hospitalization records and neonatology department registers.

Newborns assessment was established based on the following six parameters:

- Incubation $<7$ days $=1 ; \geq 7$ days or unknown $=0$;

- Period of onset $<2$ days $=1 ; \geq 2$ days or unknown $=0$; 
- Surgical entry site, burns, uterine or umbilical wounds, intramuscular injections $=1$; any other entry site or unknown $=0$;

- Spasms = 1; absence of spasm $=0$;

- Temperature $>38.5^{\circ} \mathrm{C}=1 ; \leq 38.5^{\circ} \mathrm{C}=0$;

- Pulse rate $>150 / \mathrm{min}$ in the newborn $=1$; less than 150 pulsations rate/minutes $=0$.

Then we defined severity groups according to the Dakar prognostic score:

- group I = score 0 - 1 ;

- group II = score 2 - 3;

- group III = score $4-6$ [8].

Data analysis was performed with Epi Info 7 software, version 7.1.3.3. The p-value $<0.05$ was considered significant and the odds ratio was calculated with a $95 \%$ confidence interval.

\section{Results}

Out of 5796 hospitalized newborns in the neonatology unit during the study period, 48 were identified as neonatal tetanus. The hospital frequency rate was $0.8 \%$. Among them, boys represented $52.1 \%(n=25)$ and girls $47.9 \%(n=23)$ with a sex ratio of 1.09 . The mean age was 7.7 days with extremes of 7 and 21 days. The mean term of birth was 37.8 weeks with extremes of 36 and 41 weeks of amenorrhea. They were over 7 day-old in $41.7 \%(\mathrm{n}=20)$, between 7 and 14 day-old in $47.9 \%(\mathrm{n}=23)$ and over 14 day-old in $10.4 \%(\mathrm{n}=5)$. Thirty-one newborns (64.6\%), were referred from a health facility and 17 (35.4\%), came from home. In $52.1 \%$ of cases $(\mathrm{n}=25)$, the mothers lived in Bangui and in $47.9 \%$ $(\mathrm{n}=23)$, in rural area. Their average age was 18.8 years with extremes of 15 and 27 years. The distribution of mothers according to age, gestity, parity, antenatal visits, tetanus immunization status, place of childbirth, delivery attendant, and umbilical cord cut tool are recorded in Table 1.

The duration of incubation was less than 7 days in $47.9 \%$ of newborns ( $\mathrm{n}=$ 23), between 7 and 14 days in $43.8 \%(n=2)$ and between 14 and 21 days in $8.3 \%$ $(\mathrm{n}=4)$. The mean weight was $2680 \mathrm{~g}$ with extremes of $1630 \mathrm{~g}$ and $4010 \mathrm{~g}$. It was over $2500 \mathrm{~g}$ in $66.7 \%$ of newborns $(\mathrm{n}=32)$ and less than $2500 \mathrm{~g}$ in $33.3 \%(\mathrm{n}=$ 16). Fever and spasms were noted in all cases. Inability to breastfeed and trismus were noted respectively in $81.3 \%(n=39)$ and $60.3 \%(n=29)$. Tetanus was classified as severe based on the Dakar prognostic score in $89.6 \%(n=42)$ of newborns and moderate in $10.4 \%(n=5)$ (Table 2).

The treatment of all newborn (100\%) included diazepam $(0.5 \mathrm{mg} / \mathrm{kg}$ in intrarectal followed by $0.1-0.5 \mathrm{mg} / \mathrm{kg} / \mathrm{hour}$ in continuous intravenously with electric syringe pump and $0.1 \mathrm{mg} / \mathrm{kg}$ slow intravenously if spasm while monitoring respiratory rate and targeting $8 \mathrm{mg} / \mathrm{kg} / 24$ hours), human antitetanic serum (10 UI/kg in intramuscular), first dose of Tetanus Toxoid Containing Vaccines and metronidazole $15 \mathrm{mg} / \mathrm{kg}$ every 12 hours intravenously. Amoxicillin 100 $\mathrm{mg} / \mathrm{kg} / \mathrm{day}$ and/or cefotaxime $200 \mathrm{mg} / \mathrm{kg} /$ day were associated to gentamicin 6 $\mathrm{mg} / \mathrm{kg} / \mathrm{day}$ in case of high infectious risks due to other germs. Newborns were 
Table 1. Repartition of patients according to antenatal and per-natal background.

\begin{tabular}{|c|c|c|}
\hline Variables & Number $(\mathrm{N}=48)$ & Percentage \\
\hline \multicolumn{3}{|l|}{ Age of Mother (year) } \\
\hline $15-19$ & 20 & 41.7 \\
\hline $19-23$ & 23 & 47.9 \\
\hline $23-27$ & 5 & 10.4 \\
\hline \multicolumn{3}{|l|}{ Gestity } \\
\hline Primigestes & 23 & 47.9 \\
\hline Paucigestes & 19 & 39.6 \\
\hline Multigestes & 6 & 12.5 \\
\hline \multicolumn{3}{|l|}{ Parity } \\
\hline Primipara & 33 & 68.8 \\
\hline Paucipara & 11 & 22.9 \\
\hline Multipara & 4 & 8.3 \\
\hline \multicolumn{3}{|l|}{ Number of ANC } \\
\hline One & 33 & 68.7 \\
\hline Two & 12 & 25.0 \\
\hline Three & 2 & 4.2 \\
\hline Four & 1 & 2.1 \\
\hline \multicolumn{3}{|l|}{ Mother immunization status } \\
\hline Aucune & 42 & 87.5 \\
\hline Première dose & 6 & 12.5 \\
\hline \multicolumn{3}{|l|}{ Childbirth place } \\
\hline Domicile & 44 & 91.7 \\
\hline Centre de santé & 4 & 8.3 \\
\hline \multicolumn{3}{|l|}{ Assisted Delivery } \\
\hline Assisted & 20 & 41.7 \\
\hline Non assisted & 28 & 58.3 \\
\hline \multicolumn{3}{|c|}{ Member who performed the delivery } \\
\hline Non-medical member & 24 & 50.0 \\
\hline Traditional birth attendant & 14 & 29.2 \\
\hline Midewife & 10 & 28.8 \\
\hline \multicolumn{3}{|l|}{ Umbilical cord cut tool } \\
\hline Blade & 19 & 39.6 \\
\hline Cisor & 18 & 37.5 \\
\hline Knife & 11 & 22.9 \\
\hline
\end{tabular}


Table 2. Repartition of patients according to analytic results.

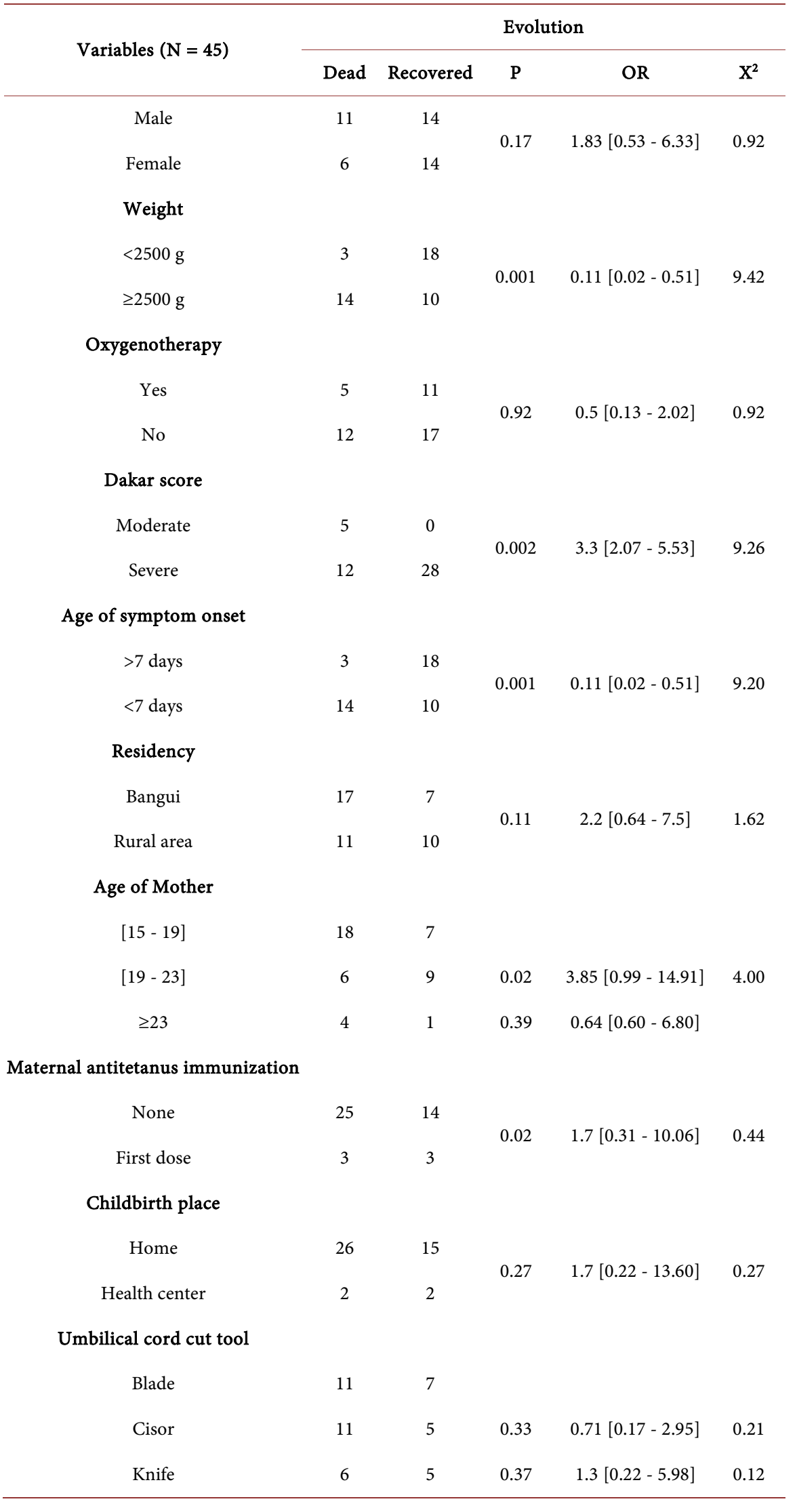


isolated from sound and light in $100 \%(\mathrm{n}=48)$. The care of the entry site was performed with Betadine. The newborn was fed with breast milk through a nasogastric tube.

The mean length of hospital stay was 8 days (extremes of 1 and 34 days). Twenty-eight newborns (58.3\%) died of which 54.2\% ( $\mathrm{n}=26)$ after hospital stay for $\leq 3$ days. The main causes of death were neonatal sepsis in $78.57 \%(n=22)$ and prematurity complications in $17.85 \%(n=5)$. The cause of death was not identified in one newborn (3.57\%). The outcome remained unknown for three newborns whose parents were discharged against medical advice. Among the 17 survived newborns, $17.64 \%(\mathrm{n}=3)$ had kept sequelae during post-hospitalization follow-up. In all cases, it was hypotonia.

Newborns to parturient under 19 year-old and those with a Dakar score between 4 and 6 , had a respective risk of death of $3.85(\mathrm{P}=0.00$; $\mathrm{OR}=3.85$ [0.99 $14.91])$ and $3.33(\mathrm{P}=0.00 ; \mathrm{OR}=3.33[0.02-0.51])$. Newborns with low birth weight, as well as those with symptoms before 7 days of life, died more often ( $\mathrm{P}$ $=0.00 ; \mathrm{OR}=0.11[0.02-0.51])$.

\section{Discussion}

The aim of this study was to contribute to the elimination of neonatal tetanus and the objectives are to determine the hospital prevalence, describe the epidemiological, clinical and therapeutic aspects as well as the outcome of hospitalized newborns for neonatal tetanus in the neonatology unit at Pediatric Teaching Hospital. The size of the sample and its realization in the single neonatal department in CAR is a major advantage. The hospital frequency of neonatal tetanus in our study: $0.8 \%$ is not negligible compared to that recorded in Mali $(0.2 \%)$ [9], and in Ivory Coast: less than 1 case per 1000 live births [10]. The difference in frequency is due, among other reasons, to the duration of the study, the difference in methods and the immunization level of the populations according to the literature data [3] [9] [10] [11] [12] [13].

Neonatal tetanus mostly observed in newborn to young mothers, is common in sub-Saharan Africa. The average age of the mothers in our study is 18.8 years. It is 21.54 years, 19 years and 23 years respectively in Sidibe, Aba and Tekpa studies [9] [10] [14]. Newborns to primipara mothers $68.8 \%(n=33)$ are the most affected, as for $46.2 \%$ in Bamako, $43 \%$ in Abidjan and $60 \%$ in Carnot serie [9] [10] [14] [15]. The high frequency of neonatal tetanus in newborns to young and primipara mothers is the witness, among others, of early sexual activities, including unintended pregnancies: cause of inappropriate follow-up; negatively impacting the quality of antenatal visits, especially the immunization. The data of our study, regarding primiparity, support the idea of the existence of barriers to access antenatal care [16]. Indeed, antenatal visits were possible for only $68.7 \%$ $(n=33)$ of the mothers in our series. Sow reported an association between the lack of antenatal care (ANC) and the occurrence of NT in 59\% of cases [13]. All of these data have for consequence the non-immunization of mothers as men- 
tioned in our study $87.5 \%(\mathrm{n}=42)$ versus $46.1 \%$ in Bamako, 56\% in Abidjan and 92.2\% in Dakar [9] [10] [11]. NT is most often occured after childbirths at home $91.7 \%(\mathrm{n}=44)$ in our study. This is also the case in $70.15 \%$ of newborns in Sow's study [11] and 23.1\% in Mali [9]. For Ribereau-Gayon [17] in Eastern Democratic Congo, the lack of hygiene during the section of the cord is exclusively the cause. He identified $100 \%$ cord suppuration. In all cases, the common denominator remains the low literacy rate, the communication deficit and the dysfunction of the health systems which, in CAR is worsened by armed conflicts [16].

Tetanus newborns are seen late on average 7.7 days. Those of 7 to 14 days (47.9\%) are the most represented. The time to diagnosis, observed during the second week of life is common in african series: 8.3 days on average for Sidibé; 7.4 days for Isik and 10 days for Mayanda [9] [12] [13]. Ribereau-Gayon [17] explained this elapsed time-often long and delaying the start of treatment-by late family decisions due to the traditional remedy and the financial barrier. However, considering the distribution of newborns according to the duration of incubation, it would be licit to attribute-besides this African reality-this admission delay to the signs onset time; assuming that the length of incubation may influence the time to admission. The majority of newborns $(52.1 \%)$ in our series were admitted after an incubation period of 7 to 21 days. In addition, late admission would result from atypical clinical forms, preventing parents from early recognition [18].

Fever, spasms, inability to breastfeed, and trismus are constant in the neonatal tetanus onset. This is confirmed in our study. In Ilé-Ifè in Nigeria or Conakry in Guinea, the majority of newborns were presented with spasms, lack of suction, and trismus [19] [20].

Regarding treatment, the respiratory monitoring instituted during the sedation of our patients did not allow us to identify adverse events related to diazepam. For neutralization of the toxin, systemic serotherapy was used. What differs from the recommendations in favor of intrathecal infusions; due to the molecular weight of tetanus immunoglobulins preventing the crossing of the bloodmeningeal barrier. Anyway, the administration time within the first 24 hours of illness onset is difficult to meet given the delay often observed in admission in developing countries. Referring to the publication of Robinson [27], intramuscular route could be preferred. As regards antibiotic therapy, we have chosen to avoid competition between penicillin G and GABA by opting for metronidazole. Co-infections, suspected or recognized as in Dakar or elsewhere [11] [19], have justified the use of probabilistic antibiotic therapy. The cases of sepsis leading to death were thus treated in our study. Sow in Dakar and Anita in Ilé Ifè [11] [19] identified them as death risk factors. The accurate causes of mortality are difficult to identify due to the lack of additional diagnostic tests in sub-Saharan settings. Other complications are to be incriminated; including vegetative complications [17], acute renal failure due to dehydration, rhabdomyolysis by muscle damage and nephrotoxicity of treatment [21]. 
Regarding the severity of the prognosis, the Dakar prognostic score $>3$, the onset of the disease $<7$ days and the birth weight $<2500 \mathrm{~g}$ are the most cited prognostic factors [11] [15] [17] [18] [19] [22] [23] [24]. The well-known severity of neonatal tetanus is found in this study in which $58.5 \%$ of newborns died. Higher mortality rates are reported [11] [17] [18].

About the sequelae, they are rarely described. Long-term follow-up in Kenya reported neurological consequences related to microcephaly, coordination disturbances, tremors, language and behavior disturbances impacting affectivity. These abnormalities are due to repeated episodes of apnea and hypoxia during a vulnerable period of brain development, but also to other factors such as hypoglycemia and sepsis [25] [26]. The tone disturbances observed upon the discharge from hospital in Bangui were not monitored; so we cannot demonstrate the permanent nature. Robinson mentioned cases of transient flaccid paralysis and one case of permanent flaccid quadriplegia in his systematic review and linked them to a direct action of the toxoid on the anterior horn of the spinal cord [27].

\section{Conclusions}

At the end of this discussion, we could admit that the pitfall constituted by the retrospective nature of this study did not alter the quality of results. These are therefore a reflection of the epidemiological situation of tetanus in Central African newborns.

Neonatal tetanus is still frequent in Bangui; it is more observed in newborns to young primipara mothers, unvaccinated and whose delivery took place at home. They are seen late and the mortality is high. The severity of neonatal tetanus requires that the management of pregnancy and childbirth be strengthened, as well as the improvement of the socioeconomic and cultural conditions of the population.

\section{Conflicts of Interest}

The authors declare no conflicts of interest regarding the publication of this paper.

\section{References}

[1] Maja, W. (2016) Le tétanos en 2016. Swiss Medical Forum, 16, 584-588. https://doi.org/10.4414/fms.2016.02699

[2] Thwaites, C.L., Beeching, N.J. and Newton, C.R. (2015) Tétanos maternel et néonatal. The Lancet, 385, 362-370.

[3] Rai, R. and Singh, D.K. (2012) Neonatal Tetanus: A Continuing Challenge. Indian Journal of Pediatrics, 79, 1648-1650. https://doi.org/10.1007/s12098-011-0666-8

[4] WHO, UNICEF, UNFPA. Eliminer durablement le tétanos maternel et néonatal: Plan stratégique 2012-2015.

http://www.who.int/immunization/diseases/MNTEStrategicPlan_F.pdf

[5] OMS. Plan d'action mondial pour les vaccins 2011-2020.

https://www.who.int/immunization/global_vaccine_action_plan/fr/ 
[6] Njuguna, H.N., Yusuf, N., Raza, A.A., Ahmed, B. and Tohme, R.A. (2020) Progress Toward Maternal and Neonatal Tetanus Elimination-Worldwide, 2000-2018. Morbidity and Mortality Weekly Report, 69, 515-520.

[7] Attinsounon, C.A., Fortes, D.L., Cissoko, Y., Diop, S.A. and Manga, N.M. (2014) Coût direct de la prise en charge hospitalière et facteurs prédictifs de mauvais pronostic du tétanos à Dakar (Sénégal). Médecine d Afrique Noire, 61, 411-416.

[8] Beytout, J., Delmont, J., Marchou, B. and Pichard, E. (2002) Manuel de maladies infectieuses pour l'Afrique. John Libbey Eurotext, Paris, 396-401.

[9] Sidibé, L.N., Coulibaly, O., Konaté, D., Diakité, F.L., Diall, H., Sacko, K., et al. (2019) Tétanos néonatal dans le service de néonatologie du CHU Gabriel Touré Département de pédiatrie. Revue Malienne d Infectiologie et de Microbiologie, 14, 68-71.

[10] Aba, Y.T., Cissé, L., Abalé, A.K., Diakité, I., Koné, D., Kadiané, J., et al. (2016) Morbidité et mortalité du tétanos des nouveau-nés et des enfants dans les Centres hospitaliers universitaires d'Abidjan, Côte d'Ivoire (2001-2010). Bulletin de la Société de Pathologie Exotique, 42, 172-179. https://doi.org/10.1007/s13149-016-0483-4

[11] Sow, P.S., Seydi, M., Diop, B.M., Dia, N.M., Manga, N.M., Diop, S.A., et al. (2003) Facteurs pronostiques du tétanos néonatal à Dakar. Médecine et Maladies Infectieuses, 33, 150-154. https://doi.org/10.1016/S0399-077X(03)00020-9

[12] Isik, Y., Nermin, G., Rejin, K., Ulker, O. and Nuran, S.A. (1992) Review of 43 Cases of Tetanus Neonatorum. The Turkish Journal of Pediatrics, 34, 121-125.

[13] Mayanda, H.E., Samba, C., Malonga, H. and Ganga Zandzou, P.S. (1998) Le tétanos néonatal: Expérience brazzavilloise de 12 cas. Annals of Pediatrics, 45, 165-170.

[14] Tekpa, G., Sepou Yanza, M.C.A., Longo, J.D.D., Inikoutiyo Mbolimonguipaïfere, J., Bogning Mejiozem, B.O., Kobalo Gbalombe, N.N., et al. (2020) Incidence et facteurs de risque du tétanos néonatal en milieu rural centrafricain. Bulletin Médical d Owendo, 18, 6-12.

[15] Oulahiane, N., Laboudi, A., Kabiri, M., Ech-cherif, E., Ehaddoury, M., Alaoui, I., et al. (2005) Le tétanos néonatal: Aspects épidémiologiques, cliniques et thérapeutiques. À propos de 34 cas. Journal de Pédiatrie et de Puériculture, 18, 38-43. https://doi.org/10.1016/j.jpp.2004.12.003

[16] OMS, Bureau régional de l'Afrique. Plan Stratégique Régional pour la Vaccination 2014-2020. 14-20.

[17] Ribereau-Gayon, R. (2000) Le traitement du tétanos en milieu rural d'Afrique de l'Est (RDC). Evaluation d'un protocole thérapeutique à propos de 21 cas. Médecine d Afrique Noire, 47, 131-138.

[18] Afshar, M., Raju, M., Ansell, D. and Bleck, T.P. (2011) Narrative Review: Tetanus-A Health Threat after Natural Disasters in Developing Countries. Annals of Internal Medicine, 154, 329-335. https://doi.org/10.7326/0003-4819-154-5-201103010-00007

[19] Davies-Adetugbo Anita, A., Torimiro, S. and Ako-Nai, K.A. (1998) Prognostic Factors in Neonatal Tetanus. Tropical Medicine and International Health, 3, 9-13. https://doi.org/10.1046/j.1365-3156.1998.00162.x

[20] Diallo, M.L., Bah, I.K., Barry, M.C., Diallo, S.B., Ondima, L.H. and Kassé, D. (2019) Tétanos néonatal : aspects épidémiologique, clinique et thérapeutique au service de pédiatrie de l'Hopital national Donka, CHU Conakry. Revue international des sciences médicales Abidjan, 21, 99-102.

[21] Daher, E.F., Abdulaker, R., Motti, E. and Marcondes, M. (1997) Prospective Study 
of Tetanus-Induced Acute Renal Dysfunction: Role of Adrenergic Overactivity. American Journal of Tropical Medicine and Hygiene, 57, 610-614. https://doi.org/10.4269/ajtmh.1997.57.610

[22] Manga, N.M., Dia, N.M., Ndour, C.T., Diop, S.A., Fortes, L., Mbaye, M., et al. (2009) Tétanos néonatal et de la femme en âge de procréer à la clinique des maladies infectieuses de Dakar. Médecine et Maladies Infectieuses, 39, 901-905. https://doi.org/10.1016/j.medmal.2008.10.011

[23] Rai, R. and Singh, D.K. (2012) Tétanos néonatal: Un défi permanent. Indian Journal of Pediatrics, 79, 1648-1650.

[24] Ka, A.S. (2012) Néonatalogie en milieu tropical. In: Imbert, P. and Minodier, P., Eds., Pédiatrie tropicale et des voyages, Collection Progros à Pédiatrie, Doin, RueilMalmaison, 23-33.

[25] Barlow, J.L., Mung Ala Odera, V., Gona, J. and Newton, C.R. (2001) Brain Damage after Tetanus in a Rural Kenyan Hospital. Tropical Medicine and Health, 6, 305-308. https://doi.org/10.1046/j.1365-3156.2001.00705.x

[26] Oulahiane, N., Ech-cherif El Kettani, S. and Alaoui, I. (2006) Tétanos néonatal. EMC (Elsevier Masson SAS, Paris), Pédiatrie-Maladies infectieuses, 4-002-R-95, 8. https://doi.org/10.1016/S1637-5017(06)72355-9

[27] Robinson, A.L. and Imbert, P. (2014) Tétanos néonatal. EMC-Pédiatrie, 49, 1-8. https://doi.org/10.1016/S1245-1789(14)67270-X 